\title{
miR-122-5p Inhibits the Proliferation, Invasion and Growth of Bile Duct Carcinoma Cells by Targeting ALDOA
}

\author{
Zhuo Xua Guangchao Liu ${ }^{\mathrm{a}}$ Meng Zhang ${ }^{\mathrm{a}}$ Zhilei Zhang ${ }^{\mathrm{a}}$ Yuming Jia ${ }^{\mathrm{a}}$ Li Peng $^{\mathrm{a}}$ \\ Yanhong Zhu ${ }^{\mathrm{b}}$ Jianbin $\mathrm{Hu}^{\mathrm{b}}$ Runying Huang ${ }^{\mathrm{b}}$ Xiaonan Sun ${ }^{\mathrm{b}}$
}

\begin{abstract}
aDepartment of Hepatobiliary Surgery, Fourth Hospital of Hebei Medical University, Shijiazhuang,

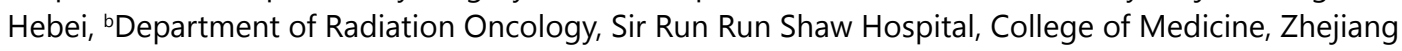
University, Hangzhou, China
\end{abstract}

\section{Key Words}

Bile duct carcinoma $\cdot \operatorname{miR}-122-5 p \cdot A L D O A \cdot$ Proliferation $\bullet$ Invasion

\begin{abstract}
Background/Aims: Bile duct cancer, although not among the most common tumors, still accounts for more and more worldwide deaths each year. By attempting to verify an overexpression of ALDOA in cholangiocarcinoma tissues and cells and explore the underlying molecular mechanism regulated by miR-122-5p, this study was designed to provide a potential molecular target in bile duct cancer treatment. Methods: Western blot and immunohistochemistry were performed to detect the ALDOA protein level in duct carcinoma tissues. The transfection efficiency was confirmed by western blot and/or RT-qPCR assay. The proliferation of bile duct carcinoma cells was determined by MTT and colony formation assay. The invasion ability of bile duct carcinoma cells was evaluated with Transwell invasion assay. Flow cytometry detected cell apoptosis of bile duct carcinoma cells. The miRNAs which modulate ALDOA were filtrated from bioinformatics software and clinical specimens. The target relationship was confirmed by dual luciferase reporter assay. Furthermore, a xenograft model was completed to verify the impact of miRNA on inhibition growth of bile duct carcinoma cells. Results: ALDOA was found up-regulated in bile duct carcinoma tissues and cells. Knockdown of ALDOA promoted the apoptosis of cells and inhibited the proliferation and invasion of bile duct carcinoma cells. Bioinformatics and clinical specimens indicated the negative correlation and targeted regulation between miR-122-5p and ALDOA. By downregulating ALDOA, overexpression of miR-122-5p appeared to promote cell apoptosis and significantly inhibit cell proliferation, invasion in vitro and suppress the tumor growth in vivo. Conclusion: miR-122-5p inhibited proliferation and invasion of bile duct carcinoma cells and promoted cell apoptosis by targeting ALDOA expression.
\end{abstract}




\section{Cellular Physiology Cell Physiol Biochem 2018;48:2596-2606

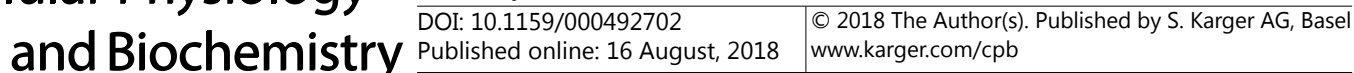 \\ Xu et al.: miR-122-5p Targets ALDOA in Bile Duct Carcinoma}

\section{Introduction}

Bile duct cancer is one of the most aggressive cancers in the world [1]. Owing to its rapid invasion and metastasis as well as the lack of accurate diagnosis in patients with bile duct cancer at an early stage, no valid therapies can be adopted for patients with any great deal of success [2]. Cytotoxic chemotherapy remains the only choice for unresectable metastatic cholangiocarcinoma (CCA). However, CCA is generally refractory to most chemotherapy, and its 5-year survival rate is extremely poor, remaining at $10 \%$ [3]. Moreover, drug resistance emerges easily in bile duct cancer, which contributes to the difficulty in clinical treatment [4]. To improve the prognosis of this disease, the investigation of targeted treatments and molecular mechanisms is needed to develop strategies for precise surgical resection.

MicroRNAs (miRNAs) are a class of short noncoding RNAs, roughly 24 nucleotides in length. miRNAs can bind to complementary sequences in the 3'untranslated regions (3'UTRs) and regulate the transcription of target genes [5]. MicroRNAs are involved directly or indirectly in diverse cancer processes by acting as tumor suppressors or oncogenes [6]. Additionally, miRNAs have recently been regarded as crucial biological regulators which modulate cell proliferation, apoptosis, cancer progression and tumorigenesis [7]. Our study has revealed that miR-122-5p plays a key role in regulating bile duct cancer. The downregulation of miR-122-5p is associated with the appearance bile duct cancer cell lines. However, the inherent biological functions and inducing mechanisms of miR-122-5p in bile duct cancer remains unknown.

It is widely accepted that $A L D O A$ is highly expressed in many kinds of harmful cancers [8], and it can function as a diagnostic biomarker. Although overexpression ALDOA has been discovered in many tumors [9], the ultimate mechanisms are undetermined and discordant. It has been assumed that $A L D O A$ expression increased because glycolysis is faster in rapidly evolving tumor cells than in normal tissues as an enzyme [10]. Yet, in other studies, ALDOA is identified as a non-metabolic in promoting cell proliferation [11]. Some studies have shown that RNA interference of $A L D O A$ is associated with carcinoma cells growth inhibition [12]. The up-regulation of $A L D O A$ in bile duct cancer has been verified by previous studies. Therefore, it is critical to elucidate the molecular mechanisms on the relationship of miRNAs and $A L D O A$, which could enhance diagnostic markers and provide an effective method in treating bile duct cancer.

As such, this study aimed to explore the potential functions and mechanisms of ALDOA in bile duct cancer and examine whether miR-122-5p was influential in the modulation of cell proliferation and apoptosis by regulating ALDOA expression in bile duct cancer. We found that the expression level of $A L D O A$ was dramatically higher in bile duct cancer tissues when compared with the corresponding normal tissues and cells. Additionally, a high miR122-5p expression level could suppress cell growth and metastasis by targeting ALDOA and impede the progress of tumor xenograft in vivo. These discoveries might present promising biomarkers and valuable therapeutic strategies in the treatment of bile duct cancer patients.

\section{Materials and Methods}

Tissues and cell culture

Paired bile duct cancer and adjacent tissue samples of two patients and other 9 bile duct cancer samples (before radiotherapy and chemotherapy, verified by histology, diameter $1-2 \mathrm{~cm}$ ) were acquired from Fourth Hospital of Hebei Medical University. The experiment was approved by the local Ethics Committee of the Fourth Hospital of Hebei Medical University. All tissues were preserved in liquid nitrogen. HIBEpiC (BNCC339778), QBC939 (BNCC339466), LIPF155C (BNCC339757), LICCF (BNCC339752), CCLP1 (BNCC339758) and RBE (BNCC100278) cells were purchased from BeNa Culture Collection (Beijing, China). HEK293T cells were provided by Fourth Hospital of Hebei Medical University. HIBEpiC, LIPF155C, CCLP1, QBC939 and HEK293T cells were routinely cultured in 90\% DMEM (Gibco, Grand Island, NJ, USA) supplemented with 10\% FBS (fetal calf serum) (Invitrogen, Carlsbad, CA, USA). LICCF and RBE cells were 


\section{Cellular Physiology Cell Physiol Biochem 2018;48:2596-2606 \begin{tabular}{l|l|l} 
and Biochemistry Published online: 16 August, 2018 & $\begin{array}{l}\text { @ } 2018 \text { The Author(s). Published by S. Karger AG, Basel } \\
\text { www.karger.com/cpb }\end{array}$ \\
\hline
\end{tabular}}

maintained in $90 \%$ RPMI-1640 containing $10 \%$ FBS (Gibco, Grand Island, NJ, USA). All cells were maintained in an incubator $\left(5 \% \mathrm{CO}_{2}\right)$ at $37^{\circ} \mathrm{C}$.

\section{Sequence acquirement}

Genetic information of $A L D O A$ (NM_000034.3) was acquired from NCBI database and the 3' untranslated region (3'UTR) sequence was obtained from UTRdb database. The miRNA sequence was extracted with UmiRBase Release 16. The miRNA sequence which potentially binds to $A L D O A$ 3'UTR was predicted by TargetScan Human 7.1.
Table 1. Sequences of siRNA and mimics used in the study

\begin{tabular}{lc}
\hline Name & \multicolumn{1}{c}{ Sequence } \\
\hline ALDOA-siRNA & 5'- GCCAGUAUGUGACCGAGAA-3' \\
control siRNA & 5'- GCCGUAUCAGUAGCGAGAA-3' \\
miR-449-5p mimics & 5'-UGGCAGUGUAUUGUUAGCUGGU -3' \\
miR-122-5p mimics & 5'- AACGCCAUUAUCACACUAAAUA -3' \\
miR-34-5p mimics & 5'- CAAUCAGCAAGUAUACUGCCCU -3' \\
mimics control & 5'- GUGCACGAAGGCUCAUCAUU-3'
\end{tabular}

Vector construction and cell transfection

ALDOA-siRNA (si-ALDOA), control siRNA (si-Con), miR-449-5p mimics, miR-122-5p mimics, miR-34$5 \mathrm{p}$ mimics and mimics control were acquired from Invitrogen, with corresponding sequences provided in Table 1. The final concentration of transfected cells was 60 nM. PcDNA ${ }^{\mathrm{TM}} 3.1(+)$ (ThermoFisher, Fremont, CA, USA) was used to construct pcDNA3.1-ALDOA overexpression vector. QBC939 and RBE cell transfections were conducted using Lipofectamine 2000 reagent (ThermoFisher, Fremont, CA, USA).

\section{Western blot (WB)}

Total proteins were extracted and measured using bicinchoninic acid (BCA) protein concentration assay kit (Beyotime, China). SDS-PAGE was utilized to separate proteins and membranes were then transferred onto PVDF membrane (Millipore, Bedford, USA) in compliance with manufacturer directions. Subsequently, $5 \%$ non-fat milk was added to block membranes for $1 \mathrm{~h}$, and they were then incubated with primary antibodies anti-ALDOA (ab169544, 1:100, Abcam, Cambridge, MA, USA) and anti-GAPDH (ab128915, 1:10000, Abcam, USA) at $4^{\circ} \mathrm{C}$ overnight. GAPDH was regarded as the endogenous control. The membranes were rinsed three times using tris buffer saline-Tween 20 (TBST) and then incubated in HRP-labeled goat anti-rabbit secondary antibody (1:2000) for $1 \mathrm{~h}$. Following this they were washed three times with TBST once more. ECL Detection System (Amersham ECL Plus ${ }^{\mathrm{TM}}$, GE12 Healthcare Life Sciences, Chalfont St. Giles, UK) was used for signal detection. All assays were performed three times.

\section{Immunohistochemistry (IHC)}

Bile duct carcinoma tissues from both patients were used for a validation analysis. After deparaffinization and rehydration, tissues were soaked in target retrieval solution (Dako) for 30 mins at $95^{\circ} \mathrm{C}$, and then blocked with PBS containing 5\% BSA. Endogenous peroxidase activity was blocked by incubation for 30 min with $0.3 \%$ hydrogen peroxide in methanol. After adding the primary antibody, a rabbit monoclonal antibody to ALDOA (ab169544, 1:5000, Abcam, Cambridge, MA, USA), incubation was performed at room temperature for $0.5 \mathrm{hr}$ in phosphate-buffered saline containing $1 \%$ bovine serum albumin in a humidified chamber. After washing, the secondary antibody conjugated to horseradish peroxidase (ab6724, 1:1000, Abcam, Cambridge, MA, USA) was incubated for over 30 minutes. The cover slips were mounted on microscope slides with 15\% Mowiol solution (Calbiochem, La Jolla, CA), and photographed using an Olympus IX71 microscope and Olympus DP72 camera, while images were processed using CCD software.

\section{MTT assay}

All the cells were kept in low-serum containing 2\% FBS (Invitrogen, Carlsbad, CA, USA) environment with starvation for $10 \mathrm{~h}$ before experiments took place. $1 \times 10^{3}$ cells/well were seeded in a 96 -well plate with $2 \%$ FBS and starved serum for $10 \mathrm{~h}$, then transfected with a corresponding vector or siRNA and cultured in normal medium. At 24, 48, 72 and $96 \mathrm{~h}$ after transfection, the MTT (3-(4, 5-dimethylthiazol-2-yl)-2, 5 -diphenyl-tetrazolium bromide) solution $(5 \mathrm{mg} / \mathrm{ml}, 20 \mu \mathrm{l})$ was added to each well. After incubation for 4 $\mathrm{h}$, the media were removed and $100 \mu \mathrm{l}$ DMSO was added to each well. The relative number of surviving cells was assessed by measuring the optical density (OD) of cell lysates at $570 \mathrm{~nm}$. All assays were performed three times. 


\section{Cellular Physiology Cell Physiol Biochem 2018;48:2596-2606 \begin{tabular}{ll|l} 
and Biochemistry Published online: 16 August, 2018 & $\begin{array}{l}\text { (c) } 2018 \text { The Author(s). Published by S. Karger AG, Basel } \\
\text { www.karger.com/cpb }\end{array}$ \\
\hline
\end{tabular} \\ Xu et al.: miR-122-5p Targets ALDOA in Bile Duct Carcinoma}

\section{Colony formation assay}

The cells were seeded in a 60mm culture dish with DMEM or RPMI 1640 with $10 \%$ FBS at a density of 400 cells per dish respectively. After incubation for 2 weeks the medium was removed and cells were washed with PBS twice, fixed in methanol for $30 \mathrm{~min}$ and stained with crystal violet solution. The colonies were counted with a microscope. All assays were performed three times.

Transwell assay

A transwell migration assay chamber was purchased from ECM550 (Chemicon, Temecula, CA, USA). The upper chamber contained serum-free medium and $0.2 \%$ BSA was added to maintain osmotic pressure in line with manufacturer instructions. The cells were placed into the upper chamber after transfection for $24 \mathrm{~h}$. Culture medium (10\% FBS) subsequently was added into the lower chamber. Following $24 \mathrm{~h}$ incubation, cells were fixed in methanol, stained with $0.1 \%$ crystal violet and counted under a microscope $(\times 200)$. Three independent experiments were performed in this method.

\section{Flow cytometry (FCM) assay}

Cells were transfected for $24 \mathrm{~h}$, digested by pancreatic enzymes and then washed twice with precooled PBS. The number of cells was adjusted to $1 \times 10^{6} / \mathrm{mL}$ with $1 \times$ Binding buffer from Annexin V-FITC (BD Biosciences, San Jose, CA, USA). $100 \mu \mathrm{l}$ cell suspension was mixed with $5 \mu \mathrm{g}$ purified recombinant Annexin $\mathrm{V}$ and reflected for 15 minutes, after which $5 \mu$ Annexin V-FITC and PI were added. The cell suspension was further incubated for $15 \mathrm{~min}$ in the dark. $400 \mu \mathrm{l} 1 \times$ Binding buffer was added and detected using flow cytometry. Three independent experiments were performed in this method.

\section{RT-qPCR}

The extraction of total RNA was performed using TRIzol reagent (Invitrogen, Carlsbad, CA, USA). The purity of RNA was measured using Nanodrop spectrophotometer (ThermoFisher, Fremont, CA, USA). The reverse transcription of miRNA was performed employing TaqMan MicroRNA Reverse Transcription Kit (ThermoFisher, Fremont, CA, USA). The complementary DNAs (cDNA) were amplified by qRT-PCR using Platinum ${ }^{\circledR}$ SYBR $\AA$ Green qPCR SuperMix-UDG (Invitrogen, Carlsbad, CA, USA). U6 was considered an endogenous control for miRNA, whereas $\beta$-actin was taken as a reference gene relative to $A L D O A$. The thermal cycling conditions for qPCR were: $95^{\circ} \mathrm{C}$ for $2 \mathrm{~min}$, followed by 40 cycles of $95^{\circ} \mathrm{C}$ for $15 \mathrm{sec}, 59.5^{\circ} \mathrm{C}$ for $30 \mathrm{sec}$ and $72{ }^{\circ} \mathrm{C}$ for $30 \mathrm{sec} .2^{-\Delta \Delta \mathrm{Ct}}$ method was applied in statistical analysis. Primers were exhibited in Table 2.

\section{Dual-luciferase reporter assay}

HEK293T cells were seeded in 24-well plates at $5 \times 10^{4}$ cells/well and cultured with serum free media for $10 \mathrm{~h}$. After this the pmirGLO-ALDOA 3'UTR-WT or -MUT reporter plasmids and miR-122-5p mimics were co-transfected into the cells. The screen mimics experiment of co-transfection of pmirGLO-ALDOA 3'UTR-WT and miR-449-5p, miR-122-5p and miR-34-5p were then conducted. Twenty-four hours after transfection, the relative luciferase activity was measured using Dual-Luciferase Reporter Assay System (Promega, Madison, WI, USA) and this was normalized against Renilla luciferase activity.

\section{Xenograft model}

20 male Balb/c mice (weight: 250-350g) were purchased from Shanghai Laboratory Animal Center (SLAC). All animal experiments were conducted in compliance with the guidelines of our Animal Ethics Committee. $1 \times 10^{7} / 0.2$ $\mathrm{ml}$ QBC939 cells and RBE cells were subcutaneously injected into Balb/c mice. After the tenth day post-injection (when the tumor could be identified by hand), $0.2 \mathrm{mg} / 0.1 \mathrm{ml} \mathrm{miR-122-}$ $5 \mathrm{p}$ mimics and control mimics were intratumorally injected. The injection frequency was three times per week and the tumor was measured using Vernier caliper. We calculated the volume of tumors with the formula of $\mathrm{V}=0.5^{*}$ length* width^ 2 every 3 days after injection and mice were not sacrificed until the $31^{\text {th }}$ day, after which the tumor tissues were separated.
Table 2. Primers used in RT-qPCR. F: forward; R: reverse

\begin{tabular}{lc}
\hline Gene & \multicolumn{1}{c}{ Primers } \\
\hline ALDOA-F & 5'-ATGCCCTACCAATATCCAGC-3' \\
ALD0A-R & 5'-GACAGCCCATCCAACCCT-3' \\
miR-122-F & 5'- GGGCTGGAGAGAGACAAT-3' \\
miR-122-R & 5'- GAATACCTCGGACCCTGC-3' \\
ß-actin-F & 5'- AGCGAGCATCCCCCAAAGTT-3' \\
ß-actin-R & 5'- GGGCACGAAGGCTCATCATT-3' \\
U6 -F & 5'-GGTCGGGCAGGAAAGAGGGC-3' \\
U6 -R & 5'- GCTAATCTTCTCTGTATCGTTCC -3' \\
\hline
\end{tabular}




\section{Cellular Physiology Cell Physiol Biochem 2018;48:2596-2606 \begin{tabular}{ll|l} 
and Biochemistry Published online: 16 August, 2018 & $\begin{array}{l}\text { (c) } 2018 \text { The Author(s). Published by S. Karger AG, Basel } \\
\text { www.karger.com/cpb }\end{array}$
\end{tabular}

\section{Statistical analysis}

SPSS 21.0 (Chicago, Illinois, USA) was used in statistical analyses. Every experiment in vitro was repeated more than 3 times and all data were documented as mean \pm SD. Differences were evaluated using unpaired Student's $t$-test and one-way ANOVA. $P<0.05$ indicated statistical significance.

\section{Results}

ALDOA was highly expressed in bile duct cancer tissues and bile duct cancer cells

With the results of WB and IHC, ALDOA protein was found to be highly expressed in bile duct cancer tissues of both patients (Fig. 1A and 1B). Following this, 5 cell lines of bile duct cancer and 1 normal cell line were assessed to detect the protein expressions of ALDOA. Compared to normal cell lines, ALDOA showed significant over-expressions in cancer cells, especially in the cell lines of QBC939 and RBE $(P<0.05)$ (Fig. 1C).

\section{ALDOA knockdown inhibited the viability of bile duct carcinoma cells}

SiRNA was used to knockdown $A L D O A$, with western blot results showing the significant down-regulation of ALDOA $(P<0.05)$ (Fig. $2 \mathrm{~A})$. Si- $A L D O A$ transfection decreased cell viability in QBC939 cells and RBE cells $(P<0.05)$ (Fig. $2 B)$ and reduced colony formation $(P<0.05)$ (Fig. 2C), showing that $A L D O A$ knockdown could significantly inhibit the proliferation of bile duct carcinoma cells. The numbers of cells permeating the septum of RBE and QBC939 were significantly reduced with $A L D O A$ knockdown $(P<0.05)$ (Fig. 2D). The cell apoptosis rate of QBC939 and RBE with $A L D O A$ knockdown increased compared with siRNA control cells (Fig. 2E).

\section{MiR-122-5p negatively regulated ALDOA expression in bile duct cancer}

According to analysis of TargetScan 7.1, miRNAs miR-122, miR-449, and miR-34 were predicted to target the 3'UTR of ALDOA (Fig. 3A). MiR-122-5p more significantly reduced the protein expression level of $A L D O A$ compared with other miRNAs in human bile duct carcinoma cell lines $\operatorname{RBE}(P<0.05)$ (Fig. 3B). MiR122-5p mimics (with mimics NC as control) and predictive target gene ALDOA3'UTR luciferase report vector co-transfected HEK293T cell tran s i e n t l y. Results showed that miR-122-5p mimics disturbed the fluorescence expression of ALDOA 3'UTR (Fig. 3C). However, neither miR-449$5 p$ nor miR-34-5p could interfere with the luciferase activity (Figure

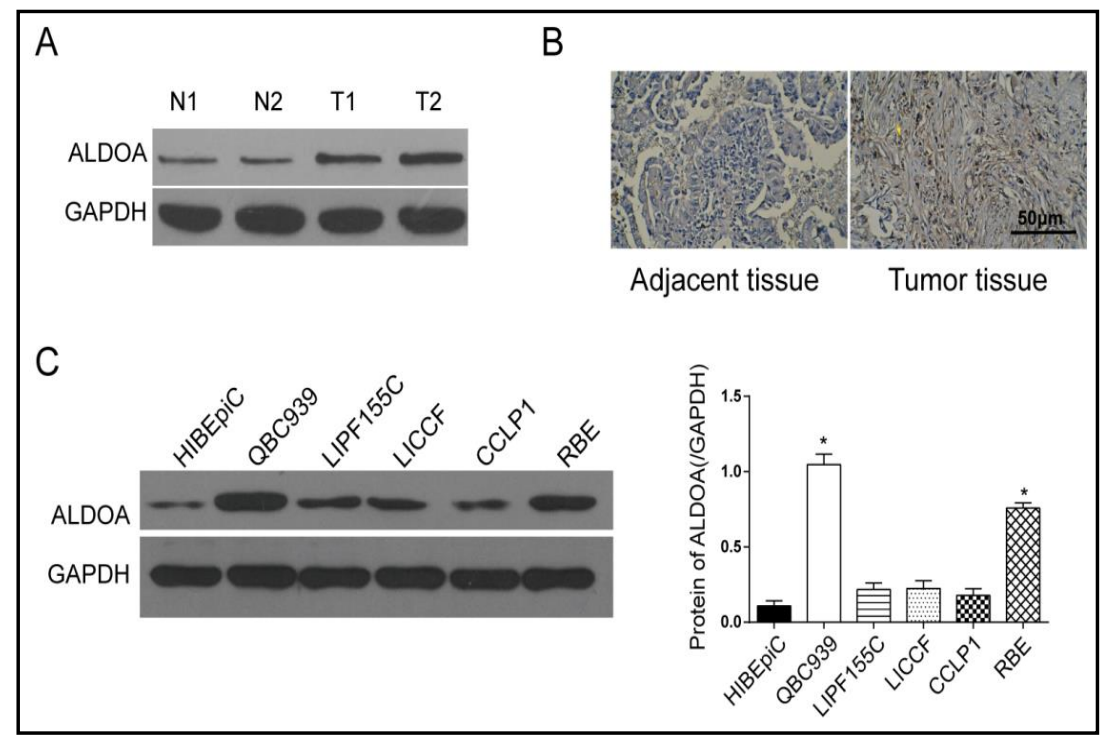

Fig. 1. ALDOA was highly expressed in bile duct cancer tissues and bile duct cancer cells ALDOA had a high expression level in cancer tissues compared with adjacent tissues as detected by western blot (A) and immunohistochemistry assay (B). Western blot detected the ALDOA protein expression level in bile duct-related cells, with cancer cells showing significantly higher levels, especially in QBC939 and RBE. ${ }^{*} \mathrm{P}<0.05$, compared with normal control (HIBEpiC). 
Fig. 2. ALDOA knockdown inhibited viability of bile duct carcinoma cells (A) SiRNA knockdown of ALDOA was confirmed by western blot. Transfected QBC939 and RBE cells with ALDOA siRNA (si-ALDOA) or siRNA control (si-Con) (B) MTT assay showed the reductive cell viability in si-ALDOA group. (C) Colony formation assay measured the inhibition of si-ALDOA on the cell proliferations (D) Transwell assay detected the reduction of invasive cells with si-ALDOA (E) Annexin V-FITC/PI double-staining reflected the increased apoptotic cells in si-ALDOA. Cells were co-stained with Annexin FITC/PI, the results were shown in a twodimensional plane with Annexin FITC staining as lateral axis and PI staining as vertical axis. Annexin FITC+/PI- cells were considered as early apoptotic cells, and Annexin FITC+/PI+ cells were considered as late apoptotic cells. ${ }^{*} \mathrm{P}<0.05$, compared with siRNA control.

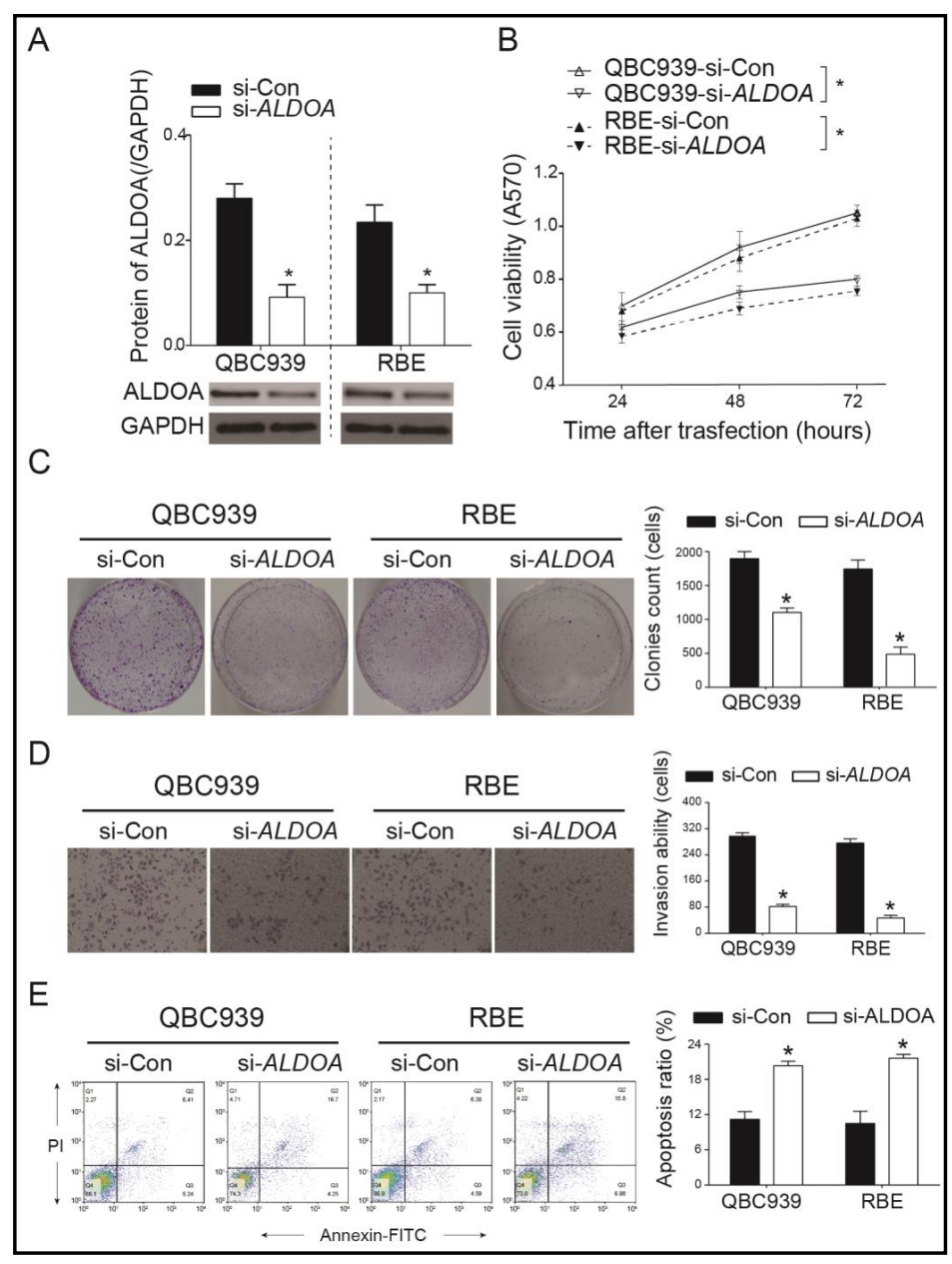

Fig. 3. MiR-122-5p targeted 3'UTR of ALDOA in bile duct cancer (A) TargetScan predicted miR-122, miR-449, and miR-34 could target ALDOA 3'UTR. (B) MiR-122-5p more significantly reduced the protein expression level of ALDOA compared with other miRNAs in human bile duct carcinoma cell lines RBE. ${ }^{*} \mathrm{P}<0.05$, compared with control mimics. (C) MiR-122-5p mimics disturbed the fluorescence expression with wild ALDOA 3'UTR. *P<0.05, compared with co-transfection of wild ALDOA 3'UTR and mimics NC. (D) ALDOA was highly expressed while miR-122-5p was reduced in tumor tissues. ${ }^{*} \mathrm{P}<0.05$, compared with the standardized normal tissues. (E) Correlation analysis showed that miR-122-5p expression and ALDOA expression had a significant negative correlation in bile duct carcinoma tissues. $\mathrm{r}=-0.6561, \mathrm{P}<0.01$.

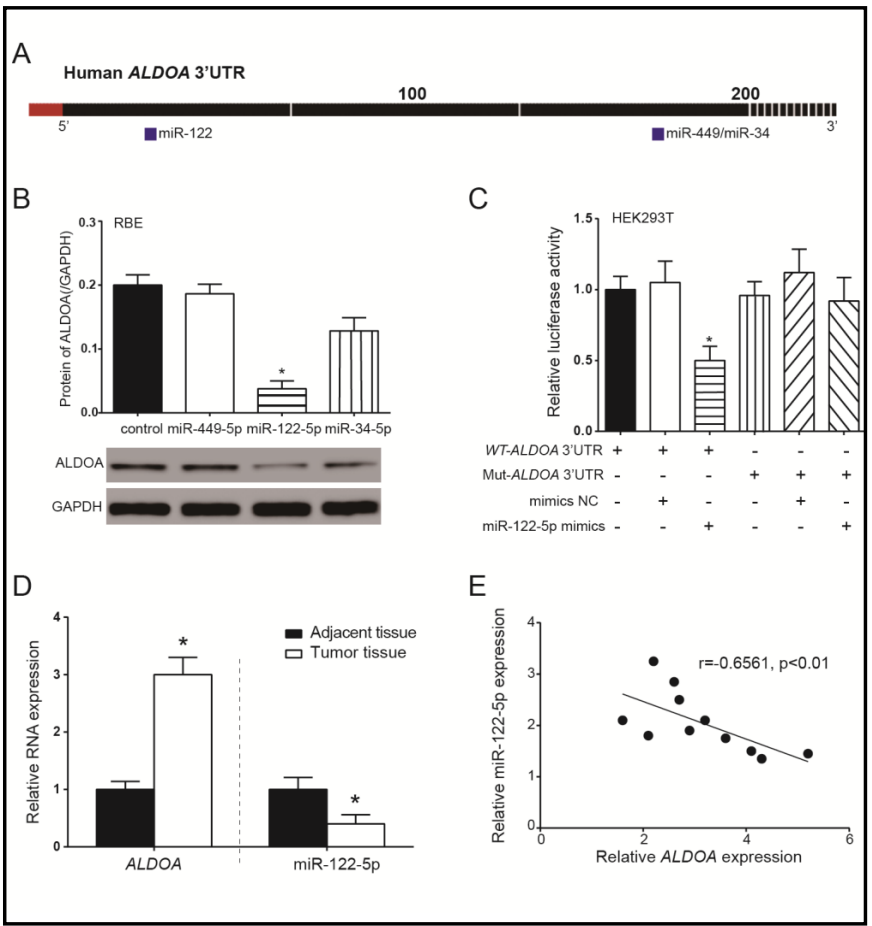


S1). For all supplemental material see www.karger. com/10.1159/000492702. High ALDOA mRNA expression was observed in bile duct carcinoma tumors and low expression was observed in normal tissues; miR-122-5p was decreased in bile duct carcinoma tumors $\quad(P<0.05) \quad$ (Fig. 3D). Correlation analysis showed that miR-122-5p expression and ALDOA expression had a significant negative correlation (Fig. 3E).

$M i R-122-5 p$ overexpression inhibited the function of QBC939 and RBE cells RT-qPCR assay indicated that miR-122-5p expression was significantly increased after miR-122$5 \mathrm{p}$ mimics transfection $(P<0.05) \quad$ (Fig. 4A). The viability of cells with miR122-5p mimics was lower than in mimics control cells $(P<0.05) \quad$ (Fig. 4B). The colony formation rate of bile duct carcinoma cells with miR-122-5p mimics was far lower than in mimics control cells $(P<0.05)$ (Fig.

4C). After transfection of miR-122-5p mimics, the number of invasive cells viewed at high power field was significantly reduced $(P<0.05)$ (Fig. 4D). In addition, miR-122-5p promoted apoptosis of QBC939 and REB cells (Fig. 4E).

MiR-122-5p overexpression antagonizes the effects of ALDOA knockdown on bile duct carcinoma cell viability, proliferation, invasion and apoptosis

ALDOA protein expression level was significantly lower in miR-122-5p mimics group, and significantly higher in pcDNA3.1-ALDOA group $(P<0.05)$. ALDOA level in miR-122$5 \mathrm{p}+A L D O A$ cells showed no significant difference with mock group (Fig. 5A). MiR-122$5 \mathrm{p}$ overexpression inhibited cell viability/proliferation/invasion in both cell lines and antagonized cell viability/proliferation/invasion induced by ALDOA overexpression $(P<0.05)$ (Fig. 5B-D \& Fig. 6A). MiR-122-5p promoted bile duct cancer cell apoptosis and reversed cell apoptosis reduction induced by ALDOA overexpression $(P<0.05)$ (Fig. 6B).

MiR-122-5p overexpression inhibited bile duct tumor growth in xenograft models

QBC939 and RBE cells were subcutaneously injected into mouse and miR-122-5p mimics or mimics control were intratumorally injected after tumor formation. Tumor size 
Fig. 5. MiR-122-5p overexpression antagonizes the effects of ALDOA knockdown on bile duct carcinoma cell viability, proliferation in RBE and QBC939 cells (A) Western blot detected the effects of transfecting ALDOA cDNA and miR-122-5p mimics on ALDOA protein. (B and C) MTT assay, (D) Colony formation assay verified that miR-122-5p can antagonize cell viability and proliferation induced by ALDOA overexpression. ${ }^{*} \mathrm{P}<0.05$, compared with mock group, \# $\mathrm{P}<0.05$, compared with ALDOA group.

in miR-122-5p overexpression group was significantly smaller $(P<0.05)$ (Fig. 7A-B). MiR-122-5p expression level in mice tumor tissues injected with miR-122-5p mimics was significantly higher than those injected with miRNA mimics control $(P<0.05)$ (Fig. 7C). In mice tumor tissues, ALDOA protein expression level was significantly lower in miR-122-5p mimics injection group $(P<0.05)$

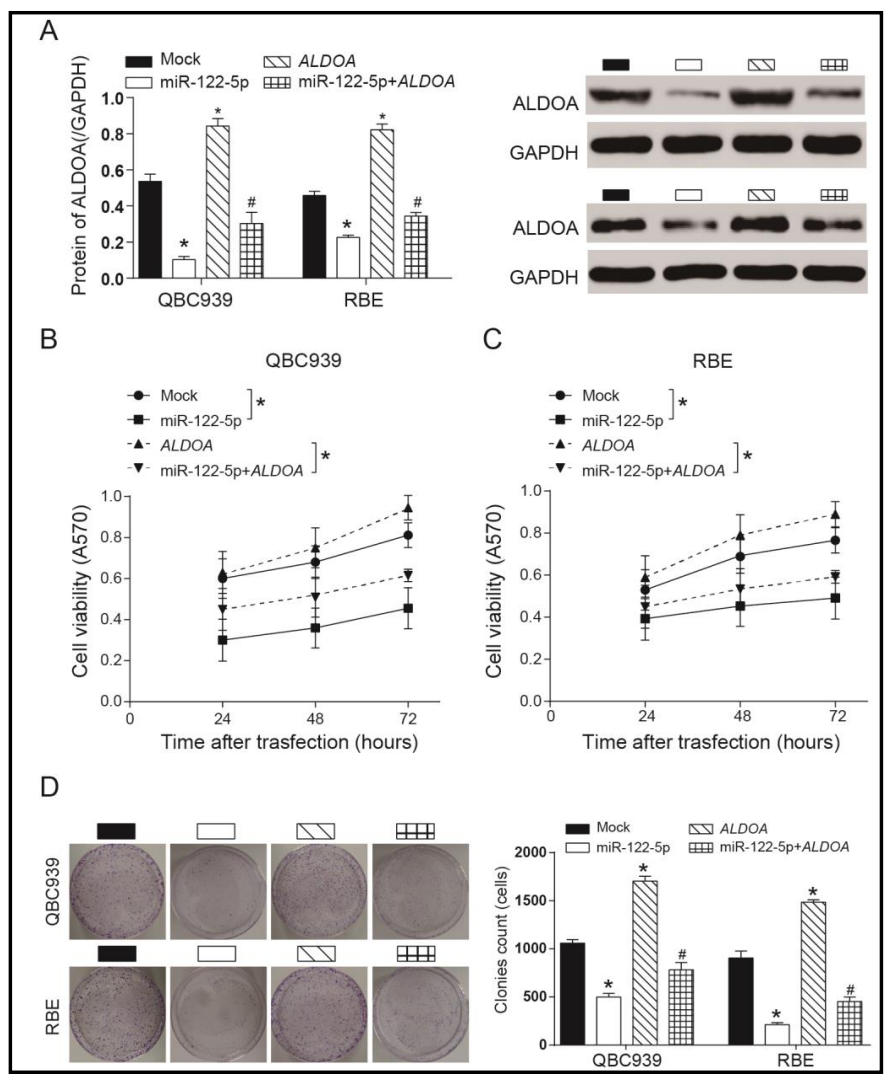
(Fig. 7D).

\section{Discussion}

The present study first demonstrated the aberrant expression of $A L D O A$ in bile duct cancer. $A L D O A$ is an omnipresent glycolytic enzyme which can control the glycolytic metabolic pathway in human cells, and it has been shown to facilitate malignant phenotypes by activating the glycolytic metabolic pathway [13]. ALDOA has been found highly expressed in lung squamous cell carcinoma, renal cell carcinoma and hepatocellular carcinoma [1316]. However, its expression in bile duct carcinoma had not been investigated prior to this research. Zhang et al. demonstrated that $A L D O A$ could facilitate the progress of non-small

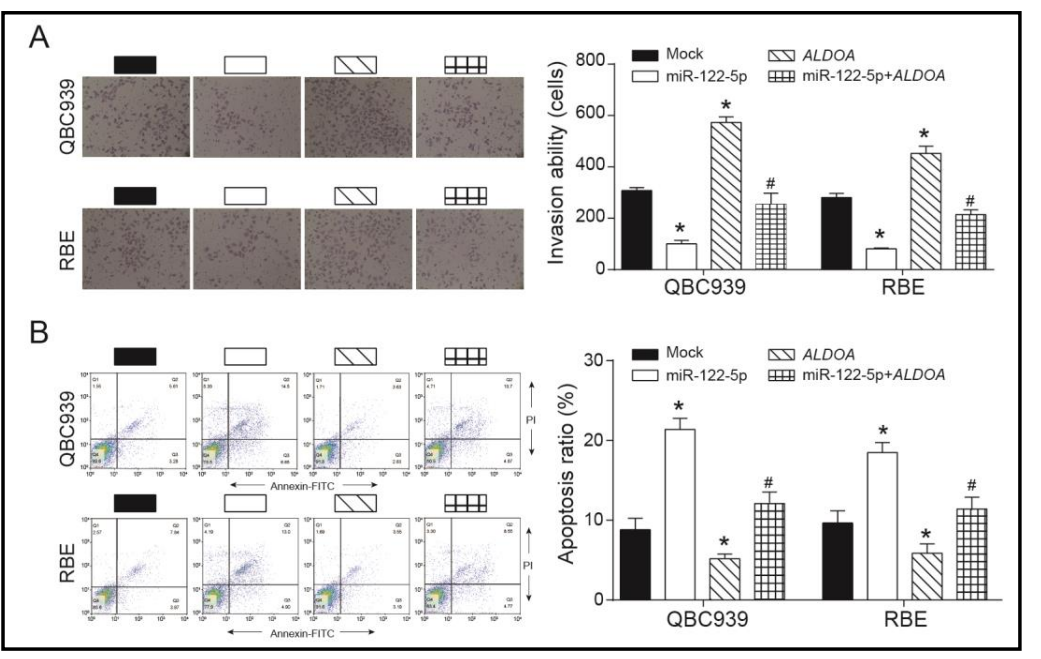

Fig. 6. MiR-122-5p overexpression antagonizes the effects of ALDOA knockdown on bile duct carcinoma invasion and apoptosis in RBE and QBC939 cells (A) Transwell assay and (B) Flow cytometry assay verified that miR-122-5p can antagonize cell invasion and apoptosis induced by ALDOA overexpression. ${ }^{*} \mathrm{P}<0.05$, compared with mock group, \# $\mathrm{P}<0.05$, compared with ALDOA group. 


\section{Cellular Physiology Cell Physiol Biochem 2018;48:2596-2606 and Biochemistry \begin{tabular}{c|c} 
DOI: 10.1159/000492702 & $\begin{array}{l}\text { O 2018 The Author(s). Published by S. Karger AG, Basel } \\
\text { www.karger.com/cpb }\end{array}$
\end{tabular}

Fig. 7. MiR-122-5p overexpression inhibited bile duct tumor growth in xenograft models. (A-B) Tumor volume at day 31 th was significantly smaller in miR-122$5 \mathrm{p}$ mimics group. Tumor tissues at day 31th were used to detect (C) the higher miR-122-5p expression in miR-122-5p mimics group by qRT-PCR. (D) the lower ALDOA protein in miR-122$5 \mathrm{p}$ mimics with western blot. $\quad{ }^{*} \mathrm{P}<0.05$, compared with miRNA mimics control.

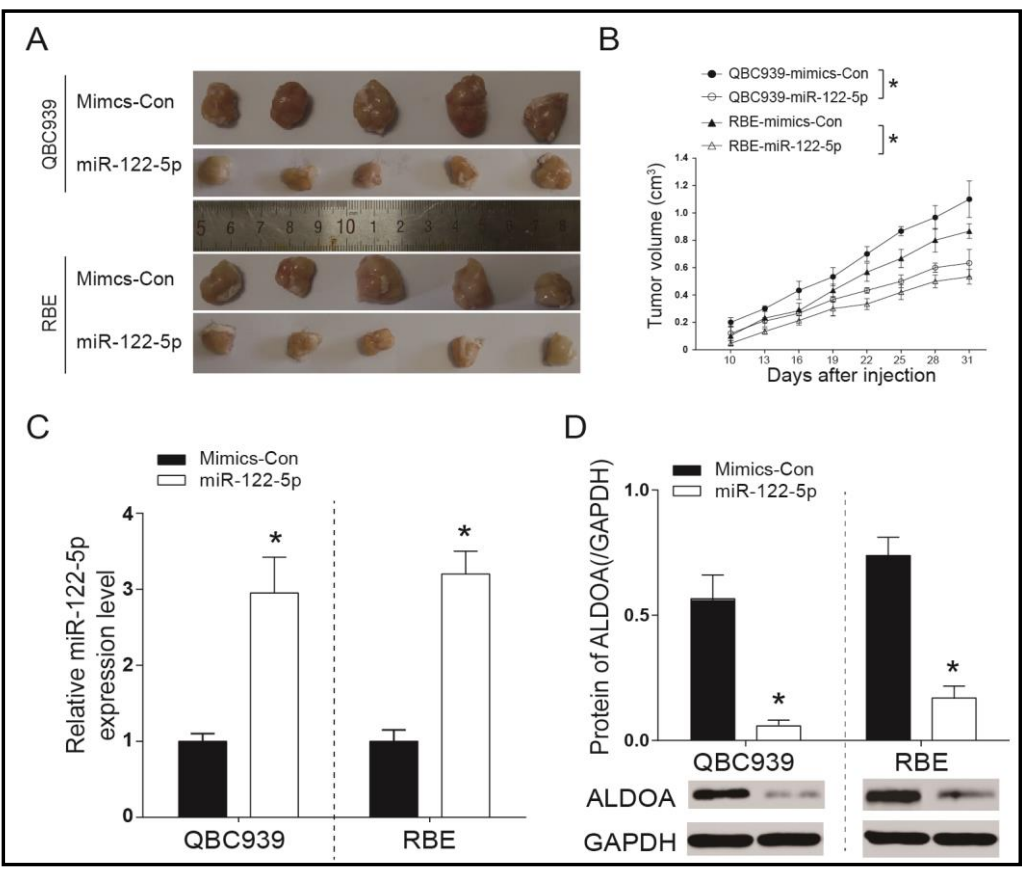

cell lung cancer by interacting with cell cycle-related genes independent of glycolysis [17]. Aside from this, Na et al. conducted multivariate analysis that revealed ALDOA as an independent and significant prognostic factor in clear cell renal cell carcinoma [18, 19]. Herein we found that $A L D O A$ was of much higher expression level in tumor tissues and cells than in normal tissues and cells. Knockdown of ALDOA in QBC939 and RBE cells attenuated the cell proliferation and induced a higher apoptosis rate. This changes could probably be attributed to the functions of $A L D O A$ in regulating glycolysis, the epithelial-mesenchymal transition and the cell cycle, as high aerobic glycolysis activity was seen in cancer progression and this is related to the inhibition of apoptosis [20]. As demonstrated by one previous study, although oxygen was presented, cancer cells still required activate glycolysis to proliferate since glycolysis affords the majority of the materials required for large-scale cell proliferation [21].

To explore the underlying mechanism for the downregulation of ALDOA in bile duct cancer, we combined the biological analysis predicted from Targetscan Database and related expression pattern of miRNAs using RT-qPCR. MiR-122-5p enlightened us with an extremely low expression in bile duct cancer tissues and a negative association with $A L D O A$ expression. MiR-122-5p plays an important role in in physiological and pathological conditions by regulating genes and is also confirmed to be a biomarker of bile duct cancer [22]. A previous study indicated that the expression of miR-122 is significantly reduced in human cholangiocarcinoma tissues, which is consistent with our research [23]. The association between miR-122-5p and ALDOA has been reported and the influence of this modulation was predicted to involve in the progression of some diseases. In silico prediction of microRNAs conducted by Raghunath et al., the Aldoa mRNA:miR-122-5p interaction in the liver was confirmed using various methods like reporter assay, western blot and qPCR [24]. MiRNAs analysis ashowed the significant down-regulation of three miRNAs (miR-122, miR-451 and miR-27) in the pathogenesis of diet-induced nonalcoholic fatty liver disease and $A L D O A$ was regarded as one of the miR-122 targets [25]. In this manuscript, we not only verified the targeted relationship between miR-122-5p and ALDOA, but also confirmed the anti-tumor influence of miR-122 with both in vitro and in vivo experiments. Upregulation of miR-122-5p reduced cell viability, attenuated cell invasion and induced cell apoptosis of both QBC939 and RBE cells. Comprehension about the functions of miR-122-5p in inhibiting tumorigenesis of bile duct cancer cells contributed a lot to the research of miRNA function in human cancers. 


\section{Cellular Physiology Cell Physiol Biochem 2018;48:2596-2606 \begin{tabular}{l|l|l} 
and Biochemistry & $\begin{array}{l}\text { DOI: 10.1159/000492702 } \\
\text { Published online: 16 August, } 2018\end{array}$ & $\begin{array}{l}\text { C) 2018 The Author(s). Published by S. Karger AG, Basel } \\
\text { www.karger.com/cpb }\end{array}$
\end{tabular}

Recently, increasing number of researches focused on the important role of long noncoding RNAs (lncRNAs), which function as miRNAs sponges and thereby promote the expression of miRNA targeted genes [26]. UCA1, HULC and MALAT1 were all reported to negatively regulate the miR-122-5p expression and functions as an oncogene lncRNA in corresponding carcinomas [27-29]. However, the reasons for the dysregulation of miR-122$5 p$ in bile duct cancers were still not clear and the related mechanism would be detailly studied in the future. Besides, the small size of clinical samples is a big limitation of this study, thus a larger size of clinical samples is required to verify the findings in further studies.

In conclusion, the results of the present study provided evidence for the first time that an overexpression of miR-122-5p could enhance cell proliferation, cell invasion and growth of bile duct cancer cells by targeting ALDOA. Furthermore, overexpression of miR-122-5p demonstrated an inverse relationship with $A L D O A$ in bile duct cancer cells via the downregulation of $A L D O A$. Consequently, the results of this study emphasized the biological role of $A L D O A / \mathrm{miR}-122-5 \mathrm{p}$ regulating the cell proliferation, invasion and growth in bile duct cancer. Therefore, $A L D O A / \mathrm{miR}-122-5 \mathrm{p}$ may be the key molecular targets in future bile duct cancer treatment.

\section{Acknowledgements}

This work was supported by Natural Science Foundation of Hebei Province (H2015206270); Hebei Provincial Government Funded Special Funds for Clinical Medical Talents in 2017. In addition, all authors approved final manuscript.

\section{Disclosure Statement}

No conflict of interests exists.

\section{References}

1 Nagakawa T, Kayahara M, Ikeda S, Futakawa S, Kakita A, Kawarada H, Matsuno M, Takada T, Takasaki K, Tanimura H, Tashiro S, Yamaoka Y: Biliary tract cancer treatment: results from the Biliary Tract Cancer Statistics Registry in Japan. J Hepatobiliary Pancreat Surg 2002;9:569-575.

- Khan S, Davidson B, Goldin R, Heaton N, Karani J, Pereira S, Rosenberg W, Tait P, Taylor-Robinson S, Thillainayagam A, Thomas H, Wasan H: Guidelines for the diagnosis and treatment of cholangiocarcinoma: an update. Gut 2012;61:1657-1669.

- 3 Rietjens S, de Lange D, Donker D, Meulenbelt J: Practical recommendations for calcium channel antagonist poisoning. Neth J Med 2016;74:60-67.

4 Vogel A, Wege H, Caca K, Nashan B, Neumann U: The diagnosis and treatment of cholangiocarcinoma. Dtsch Arztebl Int 2014;111:748-754.

5 Bartel D: MicroRNAs: target recognition and regulatory functions. Cell 2009;136:215-233.

6 Lin S, Gregory R: MicroRNA biogenesis pathways in cancer. Nat Rev Cancer 2015;15:321-333.

-7 Song J, Meltzer S: MicroRNAs in pathogenesis, diagnosis, and treatment of gastroesophageal cancers. Gastroenterology 2012;143:35-47.e32.

$>8$ Peng Y, Li X, Wu M, Yang J, Liu M, Zhang W, Xiang B, Wang X, Li X, Li G, Shen S: New prognosis biomarkers identified by dynamic proteomic analysis of colorectal cancer. Mol Biosyst 2012;8:3077-3088.

-9 Lessa R, Campos A, Freitas C, Silva F, Kowalski L, Carvalho A, Vettore A: Identification of upregulated genes in oral squamous cell carcinomas. Head Neck 2013;35:1475-1481.

10 Chen X, Yang T, Zhou Y, Wang W, Qiu X, Gao J, Li C, Long H, Ma B, Ma Q, Zhang X, Yang L, Fan Q: Proteomic profiling of osteosarcoma cells identifies ALDOA and SULT1A3 as negative survival markers of human osteosarcoma. Mol Carcinog 2014;53:138-144. 


\section{Cellular Physiology Cell Physiol Biochem 2018;48:2596-2606 \begin{tabular}{l|l|l} 
and Biochemistry Published online: 16 August, 2018 & $\begin{array}{l}\text { @ } 2018 \text { The Author(s). Published by S. Karger AG, Basel } \\
\text { www.karger.com/cpb }\end{array}$ \\
\hline
\end{tabular}

11 Mamczur P, Gamian A, Kolodziej J, Dziegiel P, Rakus D: Nuclear localization of aldolase A correlates with cell proliferation. Biochim Biophys Acta 2013;1833:2812-2822.

12 Ritterson Lew C, Tolan D: Targeting of several glycolytic enzymes using RNA interference reveals aldolase affects cancer cell proliferation through a non-glycolytic mechanism. J Biol Chem 2012;287:42554-42563.

13 Du S, Guan Z, Hao L, Song Y, Wang L, Gong L, Liu L, Qi X, Hou Z, Shao S: Fructose-bisphosphate aldolase a is a potential metastasis-associated marker of lung squamous cell carcinoma and promotes lung cell tumorigenesis and migration. PLoS ONE 2014;9:e85804.

14 Pfleiderer G, Thöner M, Wachsmuth E: Histological examination of the aldolase monomer composition of cells from human kidney and hypernephroid carcinoma. Beitr Pathol 1975;156:266-279.

-15 Chaerkady R, Harsha H, Nalli A, Gucek M, Vivekanandan P, Akhtar J, Cole R, Simmers J, Schulick R, Singh S, Torbenson M, Pandey A, Thuluvath P: A quantitative proteomic approach for identification of potential biomarkers in hepatocellular carcinoma. J Proteome Res 2008;7:4289-4298.

-16 Poschmann G, Sitek B, Sipos B, Ulrich A, Wiese S, Stephan C, Warscheid B, Klöppel G, Vander Borght A, Ramaekers F, Meyer H, Stühler K: Identification of proteomic differences between squamous cell carcinoma of the lung and bronchial epithelium. Mol Cell Proteomics 2009;8:1105-1116.

17 Hu C, Yu D, Sun X, Zhang M, Wang L, Qin H: The prevalence and progression of mild cognitive impairment among clinic and community populations: a systematic review and meta-analysis. Int Psychogeriatr 2017;29:1595-1608.

18 Na N, Li H, Xu C, Miao B, Hong L, Huang Z, Jiang Q: High expression of Aldolase A predicts poor survival in patients with clear-cell renal cell carcinoma. Ther Clin Risk Manag 2017;13:279-285.

-19 Kawai K, Uemura M, Munakata K, Takahashi H, Haraguchi N, Nishimura J, Hata T, Matsuda C, Ikenaga M, Murata K, Mizushima T, Yamamoto H, Doki Y, Mori M: Fructose-bisphosphate aldolase A is a key regulator of hypoxic adaptation in colorectal cancer cells and involved in treatment resistance and poor prognosis. Int J Oncol 2017;50:525-534.

20 Huang S, Kao J, Wu C, Wang S, Lee H, Liang S, Chen Y, Shieh J: Targeting aerobic glycolysis and HIF-1alpha expression enhance imiquimod-induced apoptosis in cancer cells. Oncotarget 2014;5:1363-1381.

21 Dang C: Links between metabolism and cancer. Genes Dev 2012;26:877-890.

-22 Karakatsanis A, Papaconstantinou I, Gazouli M, Lyberopoulou A, Polymeneas G, Voros D: Expression of microRNAs, miR-21, miR-31, miR-122, miR-145, miR-146a, miR-200c, miR-221, miR-222, and miR-223 in patients with hepatocellular carcinoma or intrahepatic cholangiocarcinoma and its prognostic significance. Mol Carcinog 2013;52:297-303.

23 Wu C, Zhang J, Cao X, Yang Q, Xia D: Effect of Mir-122 on Human Cholangiocarcinoma Proliferation, Invasion, and Apoptosis Through P53 Expression. Med Sci Monit 2016;22:2685-2690.

-24 Raghunath A, Jeyabaskar D, Sundarraj K, Panneerselvam L, Perumal E: In silico prediction of microRNAs on fluoride induced sperm toxicity in mice. Food Chem Toxicol 2016;98:34-49.

25 Alisi A, Da Sacco L, Bruscalupi G, Piemonte F, Panera N, De Vito R, Leoni S, Bottazzo G, Masotti A, Nobili V: Mirnome analysis reveals novel molecular determinants in the pathogenesis of diet-induced nonalcoholic fatty liver disease. Lab Invest 2011;91:283-293.

-26 Lorenzen JM, Thum T: Long noncoding RNAs in kidney and cardiovascular diseases. Nat Rev Nephrol 2016;12:360-373.

-27 Kong D, Wang Y: Knockdown of IncRNA HULC inhibits proliferation, migration, invasion, and promotes apoptosis by sponging miR-122 in osteosarcoma. J Cell Biochem 2018;119:1050-1061.

-28 Sun Y, Jin JG, Mi WY, Wu H, Zhang SR, Meng Q, Zhang ST: Long Non-coding RNA UCA1 Targets miR-122 to Promote Proliferation, Migration, and Invasion of Glioma Cells. Oncol Res 2018;26:103-110.

29 Xia H, Chen Q, Chen Y, Ge X, Leng W, Tang Q, Ren M, Chen L, Yuan D, Zhang Y, Liu M, Gong Q, Bi F: The lncRNA MALAT1 is a novel biomarker for gastric cancer metastasis. Oncotarget 2016;7:56209-56218. 